\title{
A primeira pessoa do plural em Santa Leopoldina/ES: correlação entre alternância e concordância
}

\section{The first plural person in Santa Leopoldina/ES: correlation between variation and agreement}

Camila Candeias Foeger ${ }^{1}$, Lilian Coutinho Yacovenco ${ }^{2}$, Maria Marta Pereira Scherre ${ }^{3}$

Mestre em Linguística, Secretaria de Estado d Educação do Espírito Santo (Sedu-ES). E-mail: camilacfoeger@gmail.com E-mail: lilianyacovenco Doutora em Linguística, Ufes/UnB/CNPq/Capes. E-mail : mscherre@gmail.com
RESUMO: Analisamos, sob o prisma da Sociolinguística Variacionista (LABOV, 2008 [1972]), dois fenômenos relativos à primeira pessoa do plural: a alternância nós/a gente e a concordância com o sujeito nós. Focalizamos o papel das variáveis linguísticas tempo verbal e saliência fônica e, também faixa etária e interação com o entrevistador. 0 corpus compõe-se por 32 entrevistas tipicamente labovianas (LABOV, 2008 [1972]), pertencentes à Amostra do Português Falado na Zona Rural de Santa Leopoldina/ES. Para a quantificação dos dados, utilizamos o programa GoldVarb X (SANKOFF; TAGLIAMONTE; SMITH, 2005). Verificamos que implementação de a gente é favorecida em contextos de "fuga à não concordância". Destacamos que (1) nós é favorecido em contextos em que há ambiguidade entre presente e pretérito perfeito: nos casos de não concordância, o morfema -mos marca o pretérito perfeito e ausência de -mos marca o presente; (2) verbos menos salientes favorecem a gente ou a ausência de concordância com nós; (3) homens de 26 a 49 anos são os que mais usam a gente; (4) o uso de nós é mais frequente quando a interação é com a entrevistadora natural da comunidade.

PALAVRAS-CHAVE: Variação nós/ a gente; Concordância verbal; Variedade rural.

ABSTRACT: In the present study, based on the perspective of Sociolinguistics Variationist (Labov, 2008 [1972]), we analyze two phenomena related to the first person plural: the alternation of first person plural nós/a gente (we) and the agreement with nós (we). We focus on linguistic variables verb tense and phonic salience, and also the age and a stylistic variable - interaction with the interviewer. The corpus used consists of 32 interviews (Labov, 2008), belonging to the Portuguese Sample Spoken in the Rural Area of Santa Leopoldina, Espírito Santo. For the quantification of data, we use the program GoldVarbX (Sankoff; Tagliamonte and Smith, 2005). We noted that the implementation of $a$ gente (we) is favored by contexts that express "run away from agreement ausence". We noted also that (1) nós is favored by present and past tense when there is ambiguity between the forms: if there is non-agreement, the morpheme -mos express past tense and the absence of the morpheme-mos express the present; (2) verbs that are less salient favor a gente or non-agreement; (3) men that have 26 to 49 years old favor a gente; (4) nós is most frequent when the interaction occurs with the interweer borned in the community.

KEYWORDS: Variation nós/a gente; Verbal agreement; Rural variety. 


\section{Introdução}

$\mathrm{N}$ o português brasileiro, duas são as formas para a designação da primeira pessoa do plural: nós - forma mais antiga ou conservadora e a gente - forma mais recente ou inovadora. A gente insere-se na língua em diversas funções sintáticas: sujeito, complemento de verbo, complemento de proposição. Na função de sujeito, nós e a gente podem variar quanto à concordância com o verbo: há presença de concordância padrão quando, junto à variante nós, o verbo apresenta desinência de $1^{\underline{a}}$ pessoa do plural (-mos) (1PP) e, junto à variante a gente, desinência de $3^{\underline{a}}$ pessoa do singular (-Ø) (3PS). Há, por outro turno, ausência de concordância quando nós surge com 3PS e a gente, com 1PP. Salientamos que a ausência de concordância é bastante estigmatizada no português brasileiro (PB), especialmente em grandes centros urbanos.

A partir da atuação das variáveis linguísticas tempo verbal e saliência fônica e, também, das variáveis faixa etária e interação com a entrevistadora, propomo-nos a evidenciar, à luz da Teoria da Variação e da Mudança Linguística (WEINREICH, LABOV \& HERZOG, 2006 [1968]; LABOV, 2008 [1972]), a inter-relação entre os fenômenos da alternância e da concordância na comunidade de fala estudada: a área rural de Santa Leopoldina. Cabe salientar que nessa comunidade a realização da concordância com a gente é semicategórica, havendo apenas um único caso sem concordância (a gente passeamos muito). Sendo assim, quanto ao fenômeno da concordância, atemo-nos apenas à relação que se estabelece com o sujeito nós.

Para o entendimento do fenômeno em terras capixabas, analisamos dados de Santa Leopoldina e estabelecemos um paralelo com os estudos realizados na capital Vitória (MENDONÇA, 2010; BENFICA, 2013). Dessa forma, cooperamos com o mapeamento do fenômeno no estado e evidenciamos a diferente distribuição do fenômeno linguístico em tela em espaços geográficos distintos: o rural versus o urbano.

Nossa hipótese é que, seguindo a tendência verificada em várias regiões brasileiras - Rio de Janeiro/RJ (OMENA, 1986; 2003), Vitória/ES (MENDONÇA, 2010), Curitiba/PR (TAMANINE, 2010), Iboruna/SP (RUBIO, 2012) e Goiás/GO (MATTOS, 2013) - também encontraremos predomínio de a gente sobre nós em Santa Leopoldina. Contudo, acreditamos que a implementação de a gente esteja em um estágio menos avançado, pois, como observa Maia (2009, p. 48), "comunidades rurais e urbanas apresentam ritmos de mudanças distintos".

Quanto ao fenômeno da concordância, pretendemos testar a hipótese de que a ausência acentuada da marca de plural em formas de 1PP seja fenômeno típico de comunidades rurais. Como ressalta Rubio (2012), reportando-se ao trabalho de Rodrigues (1987):

Ao elaborar uma comparação entre a concordância de 1PP e 3PP, a autora [Rodrigues (1987)] constatou que os índices de não-aplicação de CV para a 3PP superam em muito os índices de não-aplicação para a 1PP, pois a noção de "erro" é mais saliente para a $1 \mathrm{PP}$, sob o ponto de vista social, principalmente nos grandes centros urbanos. Essas formas são associadas a falantes do interior ou da zona rural. Segundo a autora, a noção de "erro" associada a formas em 3PP sem a variante explícita de plural não tem o mesmo peso social das formas de 1PP (RUBIO, 2012, p. 127 - grifos nossos).

\section{Referencial teórico e metodológico}

A Sociolinguística Variacionista, que se firmou na década de 1960 com a liderança de William Labov, baseia-se no uso real da língua e considera seu caráter inerentemente dinâmico e heterogêneo. Para essa corrente teórica, a variação não ocorre de modo caótico, isto é, a heterogeneidade linguística não é aleatória, mas ordenada, passível de sistematização, pois há fatores 
estruturais (linguísticos) e sociais que condicionam o uso das variantes (WEINREICH, LABOV \& HERZOG, 2006 [1968]).

Para alcançarmos os objetivos aqui delineados, selecionamos um corpus constituído por 32 entrevistas tipicamente labovianas (LABOV, 2008 [1972]), coletadas entre os meses de novembro/2011 e janeiro/2013, pertencentes à Amostra do Português Falado na Zona Rural de Santa Leopoldina ${ }^{1}$, assim distribuídas:

Quadro 1 - Composição da amostra de acordo com as variáveis sociais

\begin{tabular}{|l|c|c|c|c|c|c|c|c|c|}
\hline \multicolumn{2}{|r|}{ Idade } & $\mathbf{0 7 - 1 4}$ & \multicolumn{2}{|c|}{$\mathbf{1 5 - 2 5}$} & \multicolumn{2}{|c|}{$\mathbf{2 6 - 4 9}$} & \multicolumn{2}{|c|}{$\mathbf{5 0}-\ldots$} & Total \\
\hline Gsênero/Sexo & F & M & F & M & F & M & F & M & \\
\hline Ensino Fundamental I & 2 & 2 & 2 & 2 & 2 & 2 & 2 & 2 & 16 \\
\hline
\end{tabular}

Para a composição da amostra, consideramos as variáveis sociais faixa etária, gênero/sexo e escolaridade ${ }^{2}$. É importante ressaltar que as entrevistas foram realizadas por duas pesquisadoras: uma, natural de Santa Leopoldina, e outra, natural da Grande Vitória. Sendo assim, optamos por incluir em nosso estudo a variável interação com a entrevistadora. Consideramos esta uma variável estilística, tendo em vista a proposta de audience design, de Allan Bell (1984, p. 159): o falante, ao construir sua fala, leva em conta sua audiência, isto é, seu interlocutor, que é aquele a quem se dirige o falante, diretamente ou não.

${ }_{1}$ Amostra coletada pelas alunas-pesquisadoras Camila Candeias Foeger e Lays de Oliveira Joel Lopes, do Programa de Pós-Graduação Stricto Sensu em Linguística, da Universidade Federal do Espírito Santo, sob a orientação das professoras Lilian Coutinho Yacovenco e Maria Marta Pereira Scherre.

2 O Ensino Fundamental I compreende o primeiro ciclo do Ensino Fundamental, isto é, $1^{\underline{a}}$ à $4^{\underline{a}}$ série ou

10 ao 50 ano. Já o Ensino Fundamental II abarca as séries finais, ou seja, $5 \underline{a}$ à 8 a série ou 60 a 90 o ano.
No presente trabalho, um recorte da dissertação de Foeger (2014), analisamos as variáveis sociais faixa etária e interação com a entrevistadora. Quanto aos fatores linguísticos, focalizamos a atuação do tempo verbal e da saliência fônica. Para quantificar os dados e obter resultados estatísticos, utilizamos o programa computacional Goldvarb X (SANKOFF, TAGLIAMONTE \& SMITH, 2005), que fornece os percentuais das variantes e os pesos relativos (P.R.) dos fatores das variáveis em jogo (GUY; ZILLES, 2007).

\section{A comunidade de fala}

Santa Leopoldina localiza-se na região central serrana do estado do Espírito Santo (Fig. 1), a aproximadamente $46 \mathrm{~km}$ da capital Vitória. Sua população, segundo o censo demográfico de 2010, é de 12.140 habitantes, dos quais $78,6 \%$ residem na área rural, fazendo com que seja reconhecido como, proporcionalmente, o mais rural dos 78 municípios do estado, contrapondo-se a Vitória, que é 100\% urbano.

Histórica e culturalmente, Santa Leopoldina ocupa uma posição importante no cenário capixaba. Há uma diversidade étnica muito grande, tendo recebido imigrantes de várias nacionalidades na época de sua formação, entre os quais se destacam alemães, suíços, pomeranos, holandeses, luxemburgueses, austríacos e italianos, além de índios, portugueses e africanos que também habitavam essa região. Por muito tempo, a cidade chegou a ser o centro comercial e social mais importante do estado do Espírito Santo, pois era muito rica e avançava com progresso, sobretudo devido à navegação pelo rio Santa Maria. Entretanto, a partir da década de 1920, com o avanço das malhas rodoviárias, passou a viver uma estagnação, uma vez que "tal providência deu um golpe de morte no transporte fluvial [...], abalando desta forma os alicerces do comércio local" (SCHWARZ, 1992, p. 26). 
Figura 1 - Vista panorâmica do centro de Santa Leopoldina - perímetro urbano

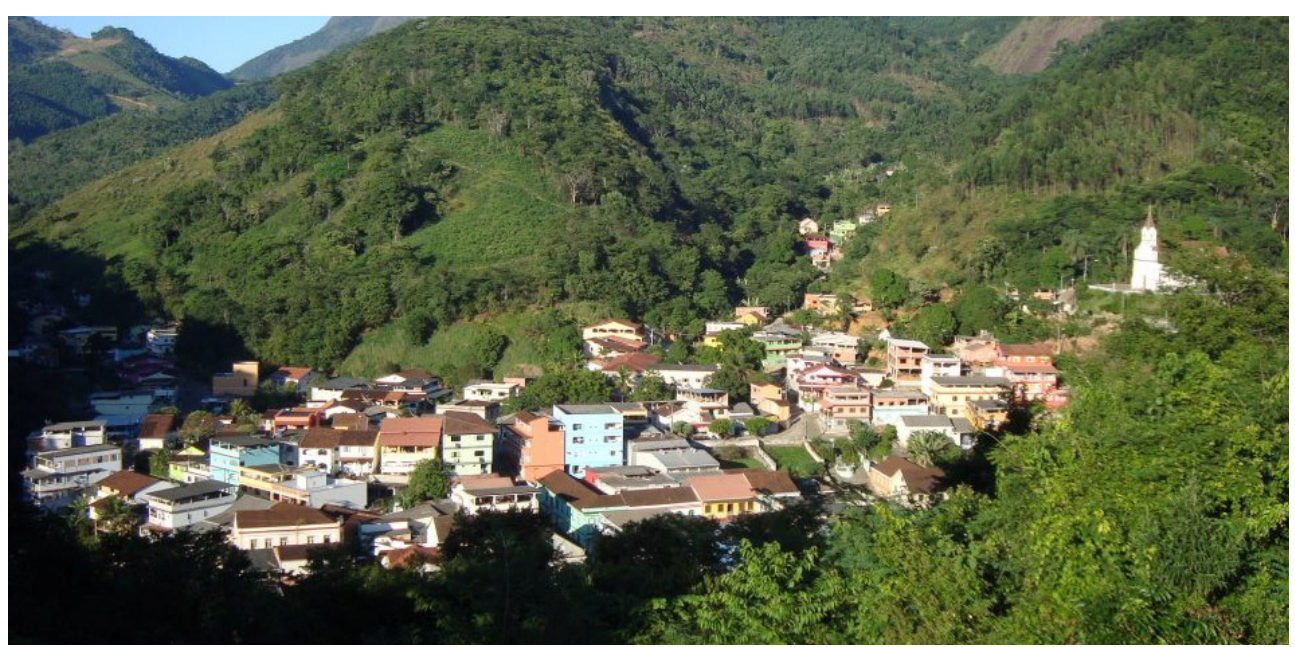

Fonte: <https://www.facebook.com/SantaLeopoldinaEs>. Acesso em: 25 fev. 2013.

A principal atividade econômica do município é a agropecuária, seguida do comércio e serviços. A estrutura fundiária retrata o predomínio de pequenas propriedades de base familiar, nas quais os trabalhos são realizados pela própria família ou no regime de parcerias agrícolas.

\section{A análise dos dados}

Do total de 2109 dados analisados em nossa pesquisa, 1136 (53,9\%) correspondem à forma a gente e $973(46,1 \%)$ a nós ${ }^{3}$. Quando comparamos esses resultados com os de Vitória, fica evidente que a substituição de nós por a gente se encontra em um estágio mais avançado na capital do estado (Gráfico 1). ${ }^{3}$ Em nossa análise, foram considerados os casos de sujeito expresso e não-expresso e, também, uma
variável independente para o controle desse aspecto.
Gráfico 1 - Comparação da distribuição de nós e a gente nas amostras de Santa Leopoldina e Vitória

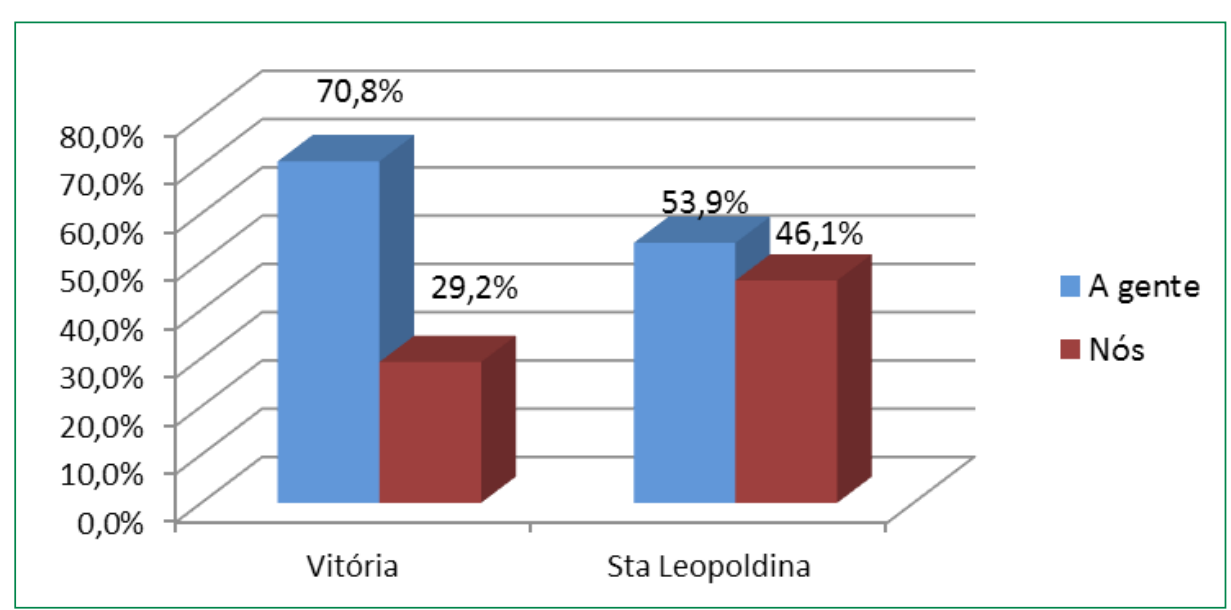

Fonte: Foeger (2014, p. 97 - Gráfico 4).

Uma das hipóteses para uma resistência maior da variante nós em Santa Leopoldina e a implementação de a gente estar mais avançada em Vitória pode estar relacionada ao fenômeno da concordância: em Vitória (BENFICA, 2013), a ausência do morfema -mos junto ao pronome nós é de cerca de $10 \%$ (46/474), enquanto em Santa Leopoldina esse índice é de 52,5\% (429/817).

Contudo, se retirássemos de nossa análise os casos de ausência de concordância, as frequências de uso das duas variantes se aproximariam, com cerca de 70\% nas duas amostras. Partimos, então, da hipótese de que em Vitória, nós é substituído por a gente a fim de evitar a não concordância, que é estigmatizada, sobretudo em centros urbanos. Na área rural de Santa Leopoldina, porém, o uso de nós sem o morfema -mos parece não carregar o mesmo estigma que na capital, daí o fato de os falantes não fazerem essa substituição com a mesma frequência no conjunto global dos dados. 


\section{Tempo verbal e saliência fônica}

Das restrições linguísticas que atuam sobre a alternância entre nós/a gente, vamos nos ater, conforme já mencionado, ao tempo verbal e à saliência fônica.

Ao analisarmos os dados, notamos que havia sobreposição dos fatores tempo e saliência e, também, que a análise estatística não apresentava convergência. Realizamos, então, o cruzamento dessas duas variáveis, gerando a seguinte configuração:

I. formas de pretérito imperfeito são denominadas Grau 1 de saliência fônica - falava/falávamos ${ }^{4}$;

II. para formas de tempo presente, há uma subdivisão em quatro níveis de saliência fônica: (1) Grau 2: fala/falamos; (2) Grau 3 - está/ estamos; faz/fazemos; (3) Grau 4 - vai/vamos; (4) Grau 5 -é/somos;

III. para formas de pretérito perfeito, há dois níveis: (1) Grau 4 - comeu/ comemos; (2) Grau 5 - falou/falamos;

IV. as ocorrências no futuro do subjuntivo e de infinitivo pessoal são por nós consideradas como Grau 6 de saliência - falar/falamos.

Para o fenômeno da alternância, verificamos que, na área rural de Santa Leopoldina, o pronome a gente é favorecido no futuro do subjuntivo (em 1), no infinitivo pessoal (em 2) e no presente (com exceção das formas mais salientes - Grau 6) (em 3), conforme observamos na Tab. 1.

(1) ainda tem um bom atendimento... porque se a gente for hoje pra Santa Maria de Jetibá ... se a gente for pra vitória lá a coisa complica... aqui ainda tá mais ou menos bom... (masculino, 26 a 49 anos, Ens. Fundamental I).

(2) foi mais um passeio pra gente ir pra:: outra fase de estudo... (masculino, 07 a 14 anos, Ens. Fundamental II).

\footnotetext{
${ }^{4}$ Os graus de saliência estão na ordem dos menos salientes para os mais salientes. Para o controle desta variável, levamos em consideração o proposto por Naro, Görski e Fernandes (1999).
}

(3) dor de cabeça... dor no estômago... algumas coisas assim... a maioria das vezes é só no chazinho né? [risos] a gente aprende muito! (feminino, 15 a 25 anos, Ens. Fundamental II).

Tabela 1 - Atuação da variável tempo verbal + saliência fônica no uso da forma a gente em Santa Leopoldina/ES

\begin{tabular}{lccc}
\hline Tempo Verbal & Aplicação/Ocorrências & $\%$ & Peso Relativo \\
\hline Pret. imp. + Grau 1: falava/falávamos & $273 / 556$ & 49,1 & 0,43 \\
Pres. + Grau 2: fala/falamos & $292 / 409$ & 71,4 & 0,71 \\
Pres. + Grau 3: está/estamos; faz/fazemos & $171 / 235$ & 72,8 & 0,57 \\
Pres. + Grau 4: vai/vamos & $55 / 90$ & 61,1 & 0,53 \\
Pres. + Grau 5: é/somos & $36 / 65$ & 55,4 & 0,40 \\
Pret. perf. + Grau 4: comeu/comemos & $49 / 151$ & 32,5 & 0,34 \\
Pret. perf. + Grau 5: falou/falamos & $69 / 256$ & 27,0 & 0,23 \\
Infinitivo + Grau 6: falar/falarmos & $57 / 80$ & 71,2 & 0,78 \\
Futuro do subj. + Grau 6: falar/falarmos & $10 / 12$ & 83,3 & 0,61 \\
Total & $1012 / 1854$ & 54,6 & \\
\hline
\end{tabular}

Fonte: Foeger (2014, p. 102 - Tab. 16).

Notamos que o tempo verbal é um fator importante, contudo é fundamental que também consideremos a atuação da saliência fônica. Por outro lado, a análise da saliência por si só também não basta, pois o grau menos saliente da nossa escala, que engloba os casos de pretérito imperfeito, não favorece a gente, e aí entram outros fatores que precisam ser considerados.

No pretérito imperfeito, como destacado por Tamanine (2010), ocorre a chamada redução de proparoxítona, um mecanismo próprio da língua para adaptar as exceções às regras, visto que o padrão acentual do português é o das paroxítonas. Nesse contexto, para se adequar, o falante pode substituir o nós por a gente ou manter o nós com o verbo sem a desinência de 1PP (nós falava). Em Vitória, Mendonça (2010, p. 84) observou que a estratégia 
utilizada pelos falantes é o uso de a gente, com percentual de $84,2 \%$ e peso relativo em 0,64 . Na área rural de Santa Leopoldina, porém, os falantes mantêm o nós e usam concordância em apenas um caso (nós não tínhamos campo de grama). Isso indica que pode haver uma percepção diferenciada da concordância nas duas comunidades: na área urbana, a ausência de concordância é fortemente estigmatizada, fato que não ocorre na área rural.

Por outro lado, ao observarmos a atuação dessas variáveis no fenômeno da concordância com a variante nós, constatamos que o fator determinante é o tempo verbal. Só há variação de fato no tempo presente. No pretérito imperfeito (em 4), no infinitivo (em 5) e no futuro do subjuntivo (em 6) a não concordância é quase categórica, com 99,7\% (1/283), 100\% (23/23) e $100 \%(2 / 2)$ de ausência de -mos, respectivamente.

(4) aí nós ficava lá embaixo no centro comunitário... depois nós vinha (masculino, 15-25 anos, Ens. Fund. II).

(5) ele reza... fala pra nós cantar cântico... (feminino, 07 a 14 anos, ensino fundamental I)

(6) se nós dois tiver junto com ele.... e se nós falar... para ele é como se não fosse falar nada (masculino, 07 a 14 anos, Ens. Fundamental I).

No pretérito perfeito e no presente do indicativo, junto a nós, há ambiguidade no caso de verbos que possuem uma única forma para designar tanto o presente quanto o passado - nós falamos. Novamente, há dois movimentos possíveis: substituir o nós por a gente (a gentefalou/a gentefala), ou manter o nós, mas reservar o -mos para marcar o pretérito (nós falamos/ nós fala), conforme já afirmado por Naro, Gorski \& Fernandes (1999). Para desfazer essa ambiguidade entre os tempos verbais, os moradores de Santa Leopoldina, se comparados com os de Vitória, usam mais frequentemente o nós, ao passo que os da capital substituem a forma conservadora por a gente. Em Santa Leopoldina, o uso da presença de concordância é praticamente categórico no pretérito perfeito $(99,7 \%)$ e a ausência do morfema -mos ocorre com bastante frequência no presente $(59,6 \%)$, sobretudo entre os falantes mais jovens, como veremos posteriormente. Em Vitória, a ausência de concordância com nós no presente é de cerca de $4 \%$ e a presença de concordância no pretérito perfeito de cerca de 98\%, ambas de efeito semicategórico (BENFICA, 2013, p. 8).

Analisando apenas o tempo presente, área de verdadeira variação em Santa Leopoldina, é possível notar o aumento da concordância à medida que aumenta o grau de saliência fônica (Tab. 2). 0 Grau 2, o único que favorece a ausência de concordância, engloba praticamente todos os verbos com ambiguidade entre as formas de presente e de pretérito. Há apenas quatro ocorrências, dos verbos poder e saber, que não apresentam ambiguidade. Cumpre notar que, dessas quatro ocorrências, apenas uma não tem concordância. $\mathrm{O}$ fator determinante, então, no presente, é a ambiguidade entre as formas de presente e pretérito. Mas, há também a atuação da saliência. Assim sendo, podemos afirmar que, no tempo presente, os verbos com ambiguidade de formas desfavorecem a concordância e, entre os verbos sem ambiguidade, os mais salientes, favorecem mais $(0,94$ e 0,91$)$ do que os menos salientes $(0,56)$.

Tabela 2 - Atuação da variável saliência fônica na realização da concordância junto ao pronome nós no tempo presente em Santa Leopoldina/ES

\begin{tabular}{lccc}
\hline $\begin{array}{l}\text { Grau de saliência fônica } \\
\text { (de -saliente para +saliente) }\end{array}$ & Aplicação/Ocorrências & $\%$ & Peso Relativo \\
\hline Grau 2: canta/cantamos & $12 / 120$ & 10,0 & 0,19 \\
Grau 3: está/estamos & $35 / 65$ & 53,8 & 0,56 \\
Grau 4: vai/vamos & $31 / 36$ & 86,1 & 0,94 \\
Grau 5: é/somos & $21 / 24$ & 87,5 & 0,91 \\
Total & $99 / 245$ & 40,4 & \\
\hline
\end{tabular}

Fonte: Foeger (2014, p. 132 - Tab. 40, com adaptações). 
Questionamos, porém, o porquê de um favorecimento da concordância bem menor no Grau 3, se os verbos não apresentam ambiguidade de formas de presente e pretérito perfeito, assim como nos graus 4 e 5 . Observamos que os verbos inseridos no Grau 3 - fazer, trazer, estar, ver e ter - têm comportamentos distintos.

O verbo fazer tem 13 ocorrências, com $100 \%$ de não concordância (em 07). O verbo trazer também aparece com essa mesma frequência relativa, mesmo com apenas um dado (em 08). 0 verbo estar, por outro lado, tem o comportamento oposto, $100 \%$ das 15 ocorrências são de concordância (em 09). 0 verbo ver também tem 100\% de concordância, mas só há uma ocorrência (em 10). Já o verbo ter apresenta variação mais equilibrada: das 35 ocorrências, 19 (54,3\%) são de concordância (em 11) e 16 (45,7\%) de não concordância (em 12).

(07) café nós faz aqui mesmo... aqui nós tem:: toca o café nosso mesmo... nós pega e:: boa qualidade demais ... aí nós:: planta/planta e colhe [inint] nós pega e faz o pó de café aqui mesmo... não compra não (masculino, 15-25 anos, Ens. Fund. II).

(08) não... nós pila e traz sempre um tanto pro nosso consumo... pilado (masculino, 15-25 anos, Ens. Fund. I).

(09) nós tamo com três hectare quase quatro... ai num dá pra cê trabalhar o ano inteiro (feminino, 26-49 anos, Ens. Fund. II).

(10) tá agora a segurança dentro do país em geral se você pegar a globalização... tá difícil! o que nós vemos hoje já perdeu-se o controle... (masculino, 50 ou + anos, Ens. Fund. I).

(11) agora a vida é boa... que graças a Deus o que nós num tinha, nós temo agora. (feminino, $50 \mathrm{ou}+$ anos, Ens. Fund. I).

(12) minha mãe assim ela não gosta de cachorro não... por causa de nós... que nós tem alergia a pelo... poeira ... (feminino, 7-14 anos, Ens. Fund. II).
Vemos então que verbos como fazer e estar, ambos sem ambiguidade de formas e com o mesmo grau de saliência fônica de estar, apresentam resultados opostos no que concerne à concordância com o sujeito nós. Parece haver outro fator, além dos mencionados, que condiciona o uso da concordância no tempo presente. Faz-se, portanto, necessário um estudo mais aprofundado para investigar esse fenômeno ${ }^{5}$.

\section{Faixa etária do falante e interação com o entrevistador}

Com respeito aos fatores sociais, destacamos a atuação da faixa etária (Tab. 3). No fenômeno da alternância, os resultados da fala rural de Santa Leopoldina são bem diversos não só dos de Vitória (MENDONÇA, 2010), mas também dos de outras regiões brasileiras, tais como Rio de Janeiro/RJ (OMENA, 1986; 2003), Curitiba/PR (TAMANINE, 2010), Iboruna/SP (RUBIO, 2012) e Goiás/GO (MATTOS, 2013). Nestas localidades, os jovens são os que mais fazem uso de a gente, ao passo que, entre os leopoldinenses, a única faixa etária que favorece essa forma inovadora é a de 26 a 49 anos.

Para explicar tal configuração da variável faixa etária na comunidade rural de Santa Leopoldina, temos duas hipóteses: a primeira seria compreender o fenômeno como um caso de gradação etária, mais especificamente relacionada ao mercado ocupacional (linguistic marketplace); a segunda via de interpretação consiste em entender o favorecimento da variante conservadora entre as pessoas mais jovens como um caso de afirmação de identidade linguística e social, semelhante ao que Labov (2008 [1972], p. 19) observou em seu estudo na comunidade de Martha's Vineyard. Discutimos, no que se segue, os aspectos relacionados a cada uma dessas alternativas.

5 Em comunicação pessoal, Naro explicitou que verbos como fazer, trazer foram considerados de Grau 2 em Naro, Görski e Fernandes (1999), tendo em vista a possibilidade de existência de uma vogal átona final nas formas de $3^{\text {a }}$ pessoa (fazi/trazi) 
Tabela 3 - Atuação da variável social faixa etária no uso de a gente em Santa Leopoldina/ES

\begin{tabular}{lccc}
\hline Faixa Etária & Aplicação/Ocorrências & $\%$ & Peso Relativo \\
07 a 14 anos & $97 / 302$ & 32,1 & 0,22 \\
15 a 25 anos & $155 / 397$ & 39,0 & 0,44 \\
26 a 49 anos & $386 / 514$ & 75,1 & 0,73 \\
50 ou + anos & $374 / 641$ & 58,3 & 0,48 \\
Total & $1012 / 1854$ & 54,6 & \\
\hline
\end{tabular}

Fonte: Foeger (2014, p. 106 - Tab. 18).

A gradação etária acontece "quando pessoas de diferentes idades usam a língua de modo distinto simplesmente porque estão em estágios diferentes de suas vidas" (TAGLIAMONTE, 2012, p. 47 - tradução nossa). Nesse caso, o indivíduo muda e a comunidade permanece estável.

A mudança de comportamento, em nossa comunidade de fala, seria mais uma questão relacionada ao mercado de trabalho, o que Sankoff e Laberge (apud MEYERHOFF, 2006), tomando a noção de linguistic marketplace, do sociólogo francês Bourdieu, entendem como a compreensão de como o modo de falar está associado à ocupação ou atividade exercida pelo indivíduo. As autoras notaram que, "muitas vezes, há um pico no uso da variante padrão nas pessoas ao atingir seus vinte e poucos anos, e depois um declínio subsequente na frequência da mesma variante entre os falantes que estão acima da meia-idade" (MEYERHOFF, 2006, p 145 - tradução nossa). No caso da alternância pronominal nós/a gente, não há polarização variante padrão e não padrão, mas podemos pensar em a gente como uma forma mais associada ao urbano e nós, ao rural, partindo do pressuposto de que a variedade rural normalmente possui um caráter mais conservador, por isso a associação ao pronome mais antigo. Há, sim, relativa oposição entre variante conservadora (nós) e variante inovadora (a gente).
Assim sendo, quando o falante está na faixa etária de maior inserção no mercado de trabalho, está também no momento de ampliação das suas relações sociais, do contato com o que é externo à comunidade rural. São os homens da faixa de 26 a 49 anos os que mais saem do local em que moram: vão ao centro da cidade para fazer compras, vão ao banco e saem até mesmo para comercializar seus produtos, e ainda há aquelas pessoas, especialmente homens, que vão à Ceasa (Centrais de Abastecimento do Espírito Santo), localizada no município de Cariacica, que faz parte da Grande Vitória.

Outra forma de interpretar esses resultados, como dissemos, é de que se trata de uma afirmação de identidade linguística e social. Podemos pensar que, na zona rural de Santa Leopoldina, um processo de mudança caminhava em direção ao pronome a gente nas faixas etárias mais velhas. Entretanto, na faixa de 15 a 25 anos, começa a haver uma reversão desse comportamento, que se expande na faixa etária que compreende os falantes de 07 a 14 anos.

Que motivações, então, há para este segundo movimento? Por que os leopoldinenses estariam afirmando o pronome nós como marca identitária? As razões para isso talvez estejam na própria história do município: em certo momento, Santa Leopoldina foi mais importante, economicamente, do que Vitória. Entretanto, hoje vive uma fase de estagnação e é o município mais rural do Espírito Santo. Há uma nítida contraposição com a capital que, nos últimos anos, teve a economia alavancada e passou a ser considerada uma das melhores capitais do país. Pode ser que essa oposição à Vitória, mesmo que inconsciente, leve os moradores da área rural de Santa Leopoldina a usarem o nós como uma maneira de marcar a importância do local, já que a outra forma - a gente - é mais nova e associada à área urbana. Por isso, os que mais usam a gente são aqueles que mais saem da comunidade, os que se encaixam na faixa de 26 a 49 anos.

Nesse sentido, é importante observarmos a atuação da variável interação com a entrevistadora, que foi considerada estatisticamente significativa 
para o fenômeno da alternância: a forma inovadora é preferida pelos leopoldinenses quando a interação é com a entrevistadora da Grande Vitória, com uma frequência de uso de 65,7\% e peso relativo em 0,68 (FOEGER, 2014, p. 111).

Quando realizado o cruzamento desta variável com a faixa etária (Tab. 4), obtemos dados interessantes. Apesar de não haver um equilíbrio na distribuição de entrevistas feitas por cada pesquisadora, é possível notar algumas tendências. As faixas das extremidades são as que mais permitem comparações, pois a quantidade de dados não é muito díspar entre as entrevistadoras.

Tabela 4 - Cruzamento das variáveis interação com a entrevistadora e faixa etária no uso de a gente em Santa Leopoldina/ES

\begin{tabular}{lcc}
\hline Faixa Etária & Natural de Sta. Leopoldina/ES & Natural da Grande Vitória/ES \\
\hline 07 a 14 anos & $21 \%(34 / 161)$ & $45 \%(63 / 141)$ \\
15 a 25 anos & $39 \%(155 / 397)$ & Não há dados \\
26 a 49 anos & $74 \%(361 / 486)$ & $89 \%(25 / 28)$ \\
50 ou + anos & $45 \%(153 / 340)$ & $73 \%(221 / 301)$ \\
Total & $51 \%(703 / 1384)$ & $66 \%(309 / 470)$ \\
\hline
\end{tabular}

Fonte: Foeger (2014, p. 111 - Tab. 20).

Os mais jovens lideram o uso do pronome nós, sobretudo quando falam diante de quem é da localidade, com apenas $21 \%$ de a gente. Quando interagem com quem é de fora, aumentam o uso de a gente para $45 \%$. Na faixa dos mais velhos, essa diferença entre as entrevistadoras é um pouco maior, de 28 pontos percentuais, com $45 \%$ de a gente na conversa com a entrevistadora natural de Santa Leopoldina e 73\% com a entrevistadora da Grande Vitória. Na faixa de plena inserção no mercado de trabalho, 26 a 49 anos, a substituição de nós por a gente é feita com mais frequência, independentemente da pessoa com quem é a interação. Entretanto, mesmo nessa faixa etária, há maior frequência de a gente quando a interação ocorre com quem é mais distante da comunidade. Esses resultados confirmam, de certo modo, que o a gente está mais associado ao urbano, enquanto o nós se evidencia como uma marca mais local.

Assim sendo, é importante buscarmos investigar também a relação dos informantes com o lugar em que vivem. Com os dados que temos, ainda não é possível estabelecermos um critério que nos permita incluir o grau de identificação do informante com a comunidade como um grupo de fatores a ser controlado. Por ora, ficam apenas delineadas as nossas interpretações.

Em nossas entrevistas, sempre perguntamos se o informante gostava de viver naquele lugar ou se gostaria de morar em outra região. Conforme visto, nossos resultados apontam que são os falantes de 25 a 49 anos os que mais desfavorecem o uso de nós. Apesar de normalmente explicitarem que gostam do lugar onde moram e que não têm a intenção de se mudarem daquela comunidade, são os que mais apontam os problemas da comunidade. Por outro lado, as pessoas que se inserem na faixa de 07 a 14 anos são as que mais favorecem a variante conservadora e também as que parecem demonstrar um maior contentamento em morar na zona rural de Santa Leopoldina. 0 ideal seria aplicarmos um teste de reação subjetiva para afirmarmos se estamos mesmo diante de uma marca identitária da comunidade.

Ante o exposto, consideramos, então, que o entendimento da atuação da variável faixa etária merece uma investigação mais detalhada. Com o que dispomos, não há como afirmar qual das duas vias de interpretação apontadas é a mais adequada. Pode ser que sejam ambas. Por enquanto, ressaltamos apenas que, na zona rural de Santa Leopoldina, a faixa etária tem um papel bem distinto do verificado em outras variedades do português brasileiro, visto que a forma inovadora não é favorecida pelos mais jovens da amostra. 
No que diz respeito ao fenômeno da concordância verbal, Santa Leopoldina também se contrapõe à Vitória (Tab. 5). Na capital do Espírito Santo, os mais jovens são os que favorecem a presença da concordância.

Tabela 5 - Efeito da variável faixa etária na concordância verbal com o pronome nós em Vitória/ES.

\begin{tabular}{lccc}
\hline Faixa Etária & Aplicação/Ocorrências & $\%$ & Peso Relativo \\
\hline 7-14 anos e 15-25 anos & $112 / 114$ & 98,2 & 0,773 \\
$26-49$ anos & $128 / 140$ & 91,4 & 0,305 \\
50 anos ou mais & $188 / 220$ & 85,5 & 0,472 \\
Total & $428 / 474$ & 90,3 & \\
\hline
\end{tabular}

Fonte: Benfica (2013, p. 7 - Tab. 2, parte).

Na área rural de Santa Leopoldina (Tab. 6), a tendência é oposta: são os mais velhos que favorecem a concordância padrão junto ao pronome nós.

Tabela 6 - Efeito da variável faixa etária na realização da concordância junto ao pronome nós no tempo presente (com a variável tempo verbal e saliência) em Santa Leopoldina/ES

\begin{tabular}{lccc}
\hline Faixa Etária & Aplicação/Ocorrências & $\%$ & Peso Relativo. \\
07 a 14 anos & $29 / 91$ & 31,9 & 0,44 \\
15 a 25 anos & $16 / 75$ & 21,3 & 0,29 \\
26 a 49 anos & $12 / 24$ & 50,0 & 0,45 \\
50 anos ou + & $42 / 55$ & 76,4 & 0,83 \\
Total & $99 / 245$ & 40,4 & \\
\hline
\end{tabular}

Fonte: Foeger (2014, p. 132 - Tab. 39, com adaptações).

É interessante notar aqui também a relação da faixa etária com a interação com a entrevistadora (Tab. 7). Apesar de esta última variável não ter sido selecionada pelo GoldVarb X como estatisticamente significativa para o fenômeno da concordância, quando conjugamos esses resultados com os da atuação faixa etária, observamos uma gradação perfeita de perda de concordância quando se está diante de quem é mais próximo à comunidade, fato que corrobora a hipótese de que a não concordância mais acentuada de $1 \mathrm{PP}$ está mais associada ao rural.

Tabela 7 - Cruzamento das variáveis interação com a entrevistadora e faixa etária na realização da concordância verbal de 1PP em Santa Leopoldina/ES

\begin{tabular}{lcc}
\hline Faixa Etária & Natural de Sta. Leopoldina/ES & Natural da Grande Vitória/ES \\
07 a 14 anos & $19 \%(10 / 52)$ & $49 \%(19 / 39)$ \\
15 a 25 anos & $21 \%(16 / 75)$ & Não há dados \\
26 a 49 anos & $48 \%(11 / 23)$ & $100 \%(1 / 1)$ \\
50 ou + anos & $74 \%(28 / 38)$ & $82 \%(14 / 17)$ \\
Total & $35 \%(65 / 188)$ & $60 \%(34 / 57)$ \\
\hline
\end{tabular}

Fonte: Foeger (2014, p. 131 - Tab. 37).

Outro traço que parece marcar a variedade rural é a elevação da vogal temática dos verbos. Como nota Bortoni-Ricardo (2011, p. 235), "na variedade caipira, a variante $/ \mathrm{mu}$ / geralmente coocorre com a mudança da vogal temática (/a/ > /e/) nos pretéritos da primeira conjugação". Em Santa Leopoldina, entre os 288 dados de concordância no pretérito perfeito, há 78 casos $(27,1 \%)$ de elevação da vogal temática. A frequência não é alta e não são todos os falantes que fazem isso, mas é algo significativo para o entendimento do português falado nessa região.

A maioria dos dados é de verbos de primeira conjugação (estudou/ estudamo(s)>estudemo) (em 13), mas também há registro de elevação da vogal temática em verbos de segunda (aprendeu/aprendemos(s)>aprendimo) (em 14) e terceira conjugação (foi/fomo(s)>fumo) (em 15). 
(13) um ano nós estudemo no posto de saúde... porque eles tavam reformando a escola (feminino, 15-25 anos. Ens. Fund. I).

(14) oh nós ia pra escola... nós não aprendimo muita coisa nessa escola justamente porque nós ia com medo pra escola (masculino, 50 ou + anos, Ens. Fund. II).

(15) cheguemo... tomemo banho e fumo dormir (masculino, 15-25 anos, Ens. Fund. II).

Em Vitória/ES não foram registradas ocorrências análogas a estudemo, aprendimo ou a fumo. É interessante observar que esse é um traço verificado na variedade popular do português europeu, como notado por Naro e Scherre (2007). Os autores localizam em terras lusitanas "a origem de estruturas linguísticas portuguesas não padrão, que em função de uma confluência de motivações, se ampliaram e se tornaram visíveis em terras hoje brasileiras" (NARO; SCHERRE, 2007, p. 23), em registros de trabalhos da dialetologia europeia. Partindo desse fato, podemos pensar na elevação da vogal temática em verbos de primeira conjugação na 1PP como uma herança do português popular europeu que ainda se conserva na área rural do Brasil. Naro \& Scherre (2007, p. 17) salienta que essas raízes linguísticas lusitanas "com mais intensidade, se revelam nas falas e nas bocas dos brasileiros que tiveram pouco acesso aos bancos escolares ou que habitam as áreas rurais e as periferias das grandes cidades", como é o caso dos falantes da nossa amostra de Santa Leopoldina. "Quem conhece a fala da área rural brasileira pode vê-la consistentemente nos registros da dialetologia europeia" (NARO; SCHERRE, 2007, p. 130).

Em nossos dados, a elevação só ocorre no pretérito perfeito. Não encontramos nenhuma ocorrência de presente do indicativo com terminação -emo. Isso indica que esse parece ser mais um mecanismo para reforçar que se está falando no pretérito e evitar a ambiguidade entre os tempos verbais.
É bom ressaltar também, que, em nossa comunidade de fala, nesse tipo de construção, o "s" é sempre suprimido.

Por último, é importante destacar que a variável escolaridade, por sua vez, não foi considerada estatisticamente significativa para nenhum dos fenômenos investigados. Isso evidencia que o prestígio está, predominantemente, nas relações sociais entre os falantes, independentemente da escola e/ou gramática.

\section{Considerações finais}

Os dois fenômenos estudados, alternância pronominal e concordância, estão intimamente imbricados e há um forte encaixamento linguístico e social. Nossos resultados confirmam que a implementação da forma inovadora se processa de modo diferente na capital do estado e na comunidade rural em estudo, reflexo da diferença de organização social dessas comunidades.

Linguística e socialmente, destacamos a implementação da forma mais nova (a gente) em contextos de "fuga à não concordância". Primeiramente, no que tange ao tempo verbal, com a forma conservadora (nós), há ambiguidade entre presente e pretérito perfeito e, o falante, para desfazê-la, substitui o nós por a gente. Quando não faz a substituição, deixa de fazer a concordância no presente, reserva o morfema -mos para marcar o pretérito e a forma zero ou ausência de -mos para marcar o presente. Nesse sentido, a saliência fônica também tem um papel importante, com verbos menos salientes, isto é, com menos diferença de material fônico entre as formas de 1PP e 3PS, há o favorecimento do uso de a gente ou a ausência de concordância com nós. Como nos centros urbanos a não concordância é mais estigmatizada que nas áreas rurais, em Vitória o falante prefere a variante a gente nesses contextos e, em Santa Leopoldina, ainda há um uso maior do pronome mais antigo (nós), mas com algumas restrições sociais. Os homens, na faixa de 
plena inserção no mercado de trabalho, 26 a 49 anos, devido ao papel que exercem na comunidade, são os que mais evitam a ausência de concordância e, consequentemente, substituem o nós por a gente.

0 pretérito imperfeito também se configura como um ambiente que favorece a forma inovadora, devido ao padrão acentual da língua, que é o das paroxítonas. Para evitar a proparoxítona, que ocorre com o pronome nós (nós falávamos), o falante usa o a gente ou deixa de fazer a concordância. Mais uma vez, as comunidades se diferenciam. Como a percepção de estigma da não concordância de 1PP é maior nos centros urbanos, em Vitória há o favorecimento de a gente e, na área rural de Santa Leopoldina, o uso dessa forma inovadora é menor.

Sendo assim, por ora, podemos dizer que a comunidade rural de Santa Leopoldina se caracteriza, em contraposição a Vitória, por uma maior conservação do pronome mais antigo, nós, e por seu uso sem a aplicação da concordância verbal, o que é corroborado pelos resultados da variável estilística interação com a entrevistadora, na medida em que o nós e a não aplicação da concordância ocorrem com mais frequência quando a interação é com a entrevistadora natural da comunidade.

Há necessidade de se ampliar a pesquisa para um melhor entendimento da atuação da variável faixa etária, que apresenta uma configuração, em Santa Leopoldina, bem diferente de Vitória e de outras localidades, com um predomínio do nós entre os mais jovens. 0 ideal, para um passo futuro, é realizar um estudo de redes sociais, entendidas como "um conjunto de vínculos de todos os tipos entre os indivíduos de um grupo" (BORTONIRICARDO, 2011, p. 15). Quanto mais fechada é a rede, maior é a tendência de se manter a linguagem minoritária não padrão. Assim, seria interessante investigar o quão densas ou fechadas são as redes sociais na área rural de Santa Leopoldina e se há uma questão de marca identitária no uso maior de nós e sem concordância.

\section{Referências}

BELL, Alan. Language style as audience design. Language in Society, v. 13, n. 2, p. 145-201, jun. 1984.

BENFICA, Samine de Almeida. Os "nós" da concordância verbal na fala capixaba. Dissertação (Mestrado em Estudos Linguísticos) - Programa de Pós-Graduação da Universidade Federal do Espírito Santo, Vitória, 2013.

BORTONI-RICARDO, Stella-Maris. Do campo para a cidade: estudo sociolinguístico de migração e redes sociais. São Paulo: Parábola Editorial, 2011.

BRAGA, Franklin Costa. Quadrazais - Etnografia e linguagem. Trabalho de conclusão (Licenciatura em Filologia Românica) - Faculdade de Letras, Universidade de Lisboa, Lisboa, 1971.

DISTRIBUIÇÃO populacional no Espírito Santo: resultados do censo demográfico de 2010. Resenha de conjuntura. IJSN, Vitória, ano IV, n. 27, maio 2011.

FOEGER, Camila Candeias. A primeira pessoa do plural no português falado em Santa Leopoldina, 2014. 158 fls. Dissertação (Mestrado em Linguística) - Universidade Federal do Espírito Santo, Vitória, 2014.

GUY, Gregory R.; ZILLES, Ana M. Sociolinguística quantitativa - instrumental de análise. São Paulo, Parábola, 2007

LABOV, William. Padrões sociolinguísticos. São Paulo: Parábola, 2008 [1972].

MAIA, Francisca Paula Soares. A variação nós a gente no dialeto mineiro: investigando a transição. Revista da Abralin, v. 8, n. 2, p. 45-70, jul./dez. 2009.

MATTOS, Shirley Eliany Rocha. Goiás na primeira pessoa do plural. 2013. $137 \mathrm{fls}$. Tese (Doutorado em Linguística) - Universidade de Brasília, Brasília, 2013.

MENDONÇA, Alexandre Kronemberguer. de. Nós e a gente em Vitória: análise sociolinguística da fala capixaba. 2010. 146fls. Dissertação (Mestrado em Linguística) Universidade Federal do Espírito Santo, Vitória, 2010.

MEYERHOFF, Miriam. Introducing sociolinguistics. New York: Routledge, 2006.

NARO, Anthony Julius; GÖRSKI, Edair; FERNANDES, Eulália Change without change. Language Variation and Change, v. 11, n. 2, p. 197-211, 1999.

NARO, Anthony Julius; SCHERRE, Maria Marta Pereira. Origens do português brasileiro. São Paulo: Parábola Editorial, 2007. 
OMENA. Nelize. Projeto subsídios sociolinguísticos do projeto censo à educação. Vol. II. Relatório final apresentado ao FINEP, out. 1986.

Referência à primeira pessoa do plural: variação ou mudança? In: PAIVA, Maria Conceição; DUARTE, Maria Eugênia Lamoglia (Org.). Mudança em tempo real. Rio de Janeiro: Capa Livraria, 2003. p. 63-80.

RUBIO, Cássio Florencio. Padrões de concordância verbal e de alternância pronominal no português brasileiro e europeu: estudo sociolinguístico comparativo. Tese (Doutorado) Universidade do Estado de São Paulo, 2012.

SANKOFF, David; TAGLIAMONTE, Salli; SMITH, E. Goldvarb X: variable rule application for Macintosh and Windows. Toronto: University of Toronto, 2005.

SCHWARZ, Francisco. O município de Santa Leopoldina. Vitória: [s.n.], 1992.

TAGLIAMONTE, Sali. Variationist Sociolinguistics: change, observation, interpretation. While-Blackwell, 2012.

TAMANINE, Andréa Maristela Bauer. Curitiba da gente: um estudo sobre a variação pronominal NÓS/A GENTE e a gramaticalização de A GENTE na cidade de CuritibaPR. 2010. 222 fl. Tese (Doutorado em Estudos Linguísticos) - Universidade Federal do Paraná, Curitiba, 2010.

WEINREICH, Uriel; LABOV, William; HERZOG, Marvin I. Empirical foundations for a theory of language change. Tradução de Marcos Bagno. São Paulo: Parábola, 2006 [1968].

Recebido em 28/08/2016.

Aceito em 13/02/2017. 